\title{
Reaching the full potential of MEP monitoring during surgery of the thoracoabdominal aorta
}

\author{
Brent Keeling, MD, and Edward P. Chen, MD
}

\author{
From the Division of Cardiothoracic Surgery, Emory University School of Medicine, Atlanta, Ga. \\ Disclosures: Authors have nothing to disclose with regard to commercial support. \\ Received for publication Oct 13, 2015; accepted for publication Oct 18, 2015; available ahead of print Nov 13, \\ 2015 . \\ Address for reprints: Edward P. Chen, MD, Division of Cardiothoracic Surgery, Emory University School of \\ Medicine, 5665 Peachtree Dunwoody Rd, Ste 200, Atlanta, GA 30342 (E-mail: epchen@emory.edu). \\ J Thorac Cardiovasc Surg 2016;151:518-9 \\ $0022-5223 / \$ 36.00$ \\ Copyright (c) 2016 by The American Association for Thoracic Surgery \\ http://dx.doi.org/10.1016/j.jtcvs.2015.10.043
}

Ischemia of the spinal cord is a devastating source of major morbidity following repair of a thoracoabdominal aorta and a significant clinical driver of perioperative mortality. In large series published by high-volume centers of excellence, the incidence of spinal cord ischemia was approximately $5 \%$ and its incidence varies according to extent of aneurysmal involvement and the subsequent aortic replacement required for adequate repair. ${ }^{1}$ During the past 2 decades, several intraoperative protective adjuncts have been incorporated into the surgical strategies aimed at reducing the incidence postoperative spinal cord injury. Such techniques include continuous distal aortic perfusion, drainage of cerebrospinal fluid, and permissive hypertension. Distal aortic perfusion can encompass many possible strategies, such as left heart bypass, partial or full cardiopulmonary bypass, and circulatory arrest with deep hypothermia. Despite these clinical advances, the ability to detect intraoperative spinal cord ischemia injury both quickly and accurately in real time as well as institute therapeutic measures directed toward reversing such injury remains a significant clinical concern.

Tsuda and colleagues ${ }^{2}$ attempt to address 1 current area of concern regarding the use of continuous motor evoked potentials (MEPs) monitoring during open thoracoabdominal aneurysm repair. The most common method of monitoring intraoperative MEPs is via the transcranial (TC) route, yet the authors convincingly argue that the prognostic value of TC-MEPs is relatively poor and unreliable. Previous work in this field has demonstrated that for thoracoabdominal aortic surgery, the negative predictive value of MEPs is strong, but the correlations go no further. ${ }^{3}$ As a result, Tsuda and colleagues ${ }^{2}$ examined the potential benefit of using transesophageal (TE) monitoring of MEPs using conventional TC-MEP equipment to detect spinal cord injury.

Using an elegant experimental design, a canine model of induced spinal cord ischemia was carried out using balloon aortic occlusion. Six dogs were monitored with TC-MEP, whereas another 6 were monitored with TE-MEP at 2

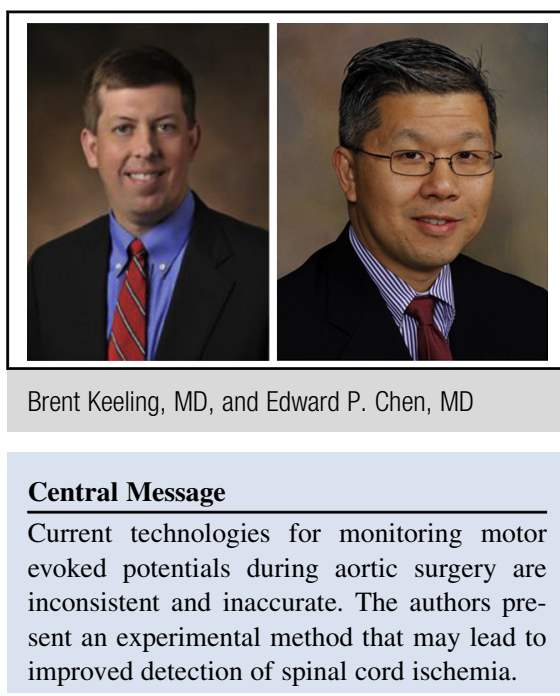

See Article page 509.

different time points of ischemia. In short, the results generated by TE-MEP were more accurate and quicker to disappear and reappear compared with signals generated by TC-MEP. Given the relatively short duration of ischemia that the spinal cord will tolerate, accurate deviation of MEP signals occurring in a rapid manner may afford surgeons an opportunity to act quickly and initiate therapeutic measures to prevent or reverse ongoing spinal cord ischemia and injury. TE-MEP may have the additional advantage of being able to detect spastic paraplegia (as was seen in 1 experimental animal) compared with TC-MEP.

An additional important contribution of this study centers on the pathologic specimens of the spinal cords in animals that ultimately developed paraplegia. The injuries were not homogeneous, suggesting a multifocal pattern of paraplegia in this experiment. These pathologic patterns of spinal cord injury have potential implications on further preventive adjuncts as we gain additional understanding these injuries.

One important question remains: How should aortic surgeons interpret this experimental study and its results? Whereas it is clear that further clinical studies in humans will be necessary to validate the experimental successes of TE-MEP monitoring, the work is promising. Given the theorized increased sensitivity to spinal tract function, TE-MEP may eventually replace TC-MEP by those surgeons currently employing such monitoring techniques as part of their intraoperative armamentarium. For those surgeons who do not currently employ MEP monitoring 
during thoracoabdominal aortic surgery, the increased accuracy and sensitivity of TE-MEP may ultimately lead to increased application of this technology on a routine basis. If it is eventually demonstrated that disturbances in the TE-MEP signals occur more accurately and rapidly than TC-MEP signals in the intraoperative setting, surgeons will have a much more reliable tool for monitoring spinal cord ischemia and increased potential for instituting measures to reverse such injury. This improvement would represent a significant advancement in open surgical repair of the thoracoabdominal aorta and may ultimately lead to lower rates of postoperative paraplegia in these highly complex procedures.

\section{References}

1. LeMaire SA, Price MD, Green SY, Zarda S, Coselli JS. Results of open thoracoabdominal aortic aneurysm repair. Ann Cardiothorac Surg. 2012;1: 286-92.

2. Tsuda K, Shiiya N, Takahashi D, Ohkura K, Yamashita K, Kando Y, Arai Y. Transesophageal versus transcranial motor evoked potentials to monitor spinal cord ischemia. J Thorac Cardiovasc Surg. 2016;151:509-17.

3. Keyhani K, Miller CC III, Estrera AL, Wegryn T, Sheinbaum R, Safi HJ. Analysis of motor and somatosensory evoked potentials during thoracic and thoracoabdominal aortic aneurysm repair. J Vasc Surg. 2009;49:36-41. 